\title{
Study on Double-Shear Test of Anchor Cable and C-Shaped Tube
}

\author{
Renliang Shan $\mathbb{D}$, Yongsheng Bao $\mathbb{D}$, Pengcheng Huang $\mathbb{D}$, Weijun Liu $\mathbb{D}$, \\ and Gengzhao Li 1 \\ School of Mechanics and Civil Engineering, China University of Mining and Technology (Beijing), Beijing 100083, China \\ Correspondence should be addressed to Pengcheng Huang; huangpengcheng@student.cumtb.edu.cn
}

Received 10 March 2021; Revised 21 April 2021; Accepted 15 May 2021; Published 27 May 2021

Academic Editor: Zhixiong Li

Copyright (C) 2021 Renliang Shan et al. This is an open access article distributed under the Creative Commons Attribution License, which permits unrestricted use, distribution, and reproduction in any medium, provided the original work is properly cited.

\begin{abstract}
The free section of prestressed anchor cable is a weak part of support. A new supporting structure named Anchor Cable and C-Shaped Tube, which can bear transverse shear force, solves the problem that rock bolt and anchor cable are prone to shear failure in the free section and also solves the contradiction between high preload and low shear bearing capacity of support materials. Double-shear tests of Anchor Cable and C-Shaped Tube with smooth joint planes were carried out. Double-shear tests were carried out on the anchor cables with the diameter of $21.6 \mathrm{~mm}$ and the same type of Anchor Cable and C-Shaped Tube under different preload conditions. The influence of the preload on the shear performance of supporting materials and the enhancement effect of Anchor Cable and C-Shaped Tube supporting structure on the shear performance of anchor cables were analyzed. The test results confirm that Anchor Cable and C-Shaped Tube can improve the transverse shear resistance of the supporting material and increase the axial ultimate bearing capacity of the anchor cable during the shearing process. It is found that, during the doubleshear test, the fracture form of the supporting materials is tensile fracture, and when it is sheared, Anchor Cable and C-Shaped Tube can reduce the stress concentration of the interaction between the joint surface and the surrounding rock and reduce the damage to the surrounding rock.
\end{abstract}

\section{Introduction}

The use of rock bolts and anchor cables has become an important and main support method for coal mine roadway support [1]. With the increasing depth of coal mining, the changeable geological structure in the environment of deep underground, the complex stress environment, and the large common deformation and failure of surrounding rock appear, while the conventional supporting methods show limitations $[2,3]$. Due to the inadaptability of ordinary anchor cables of the large deformation environment of surrounding rock, the breaking phenomenon occurs constantly, and the forms are different [4]. Besides the most common tensile breaking, there are also a large proportion of shear breaking, tension bending, and tension-shear combined breaking forms [5-9].

At present, in the design of roadway support, most of them only put axial bearing capacity into consideration without shear bearing capacity of rock bolt and anchor cable, and the shear fracture of rock bolts and anchor cables cannot be ignored [10]. Some studies have found that the fracture location of the anchor cable or rock bolt occurs at the position of the free section near 2 meters above the roof of the roadway [11], and other studies have found that the ultimate bearing capacity and displacement of anchor cable will decrease with the increase of prestress $[12,13]$, which improves the probability of shear breaking of anchor cable. Therefore, the free section of the prestressed anchor cable is a weak link that is susceptible to shear failure. Lin et al. studied the anchorage stress and deformation of the anchorage joint under shear action through direct shear test and found that the inclination angle of the bolt has an effect on the shear strength of the joint plane and improved the shear creep model of rock-like materials $[14,15]$.

In order to adapt to the large deformation characteristics of deep surrounding rock, many supporting materials and supporting technologies have been invented by experts and scholars. For instance, anchor bolt with constant resistance and large deformation and NPR bolts/cables invented by He et al. well solved the problem of large deformation in deep soft rock roadway [16-18]. Also, the team of Kang et al. found that the prestress of rock bolt and its diffusion played a 
decisive role in supporting effect and proposed a high prestress and high strength supporting system, which achieved good results in many work sites [19-21]. Most of these technologies and materials aim at controlling the large axial deformation of surrounding rock but seldom consider the transverse loading of supporting materials. In order to solve the contradiction that the supporting material in free section is easy to break and the transverse bearing capacity and transverse displacement of the supporting material are easy to decrease due to high prestress [11-13], a supporting structure named Anchor Cable and C-Shaped Tube was invented to solve the problem that the anchor cable with high prestress in free section is easy to shear and break. The shear mechanical properties of the supporting structure named Anchor Cable and C-Shaped Tube were studied by double-shear tests in laboratory. In this provision, Anchor Cable and C-Shaped Tube shall hereafter be referred to as ACC.

\section{Brief Introduction of ACC and Analysis of Its Mechanism}

2.1. Brief Introduction of ACC Supporting Structure. ACC consists of two parts, anchor cable with high prestress and $\mathrm{C}$-shaped tube. Figure 1 shows the physical drawing and schematic of ACC. The anchor cable with high prestress exerts axial compression force on the structural plane of surrounding rock by prestress, which increases the friction between joint planes, prevents the surrounding rock from dislocation on both sides of the structural plane, together with the dowelling function of anchor cable itself, and prevents the surrounding rock from axial shearing dislocation. The C-shaped tube is installed at the free end of the structure, which separates the exposed part of anchor cable or rock bolt from surrounding rock [22]. When shear dislocation occurs in surrounding rock, it would be separated from the free end of anchor cable or rock bolt. With the shear deformation of the structural plane, the C-shaped tube shrinks gradually to completely wrap the anchor cable, thus improving the shear stiffness and increasing the shear capacity of the free end of the supporting structure.

2.2. Analysis of the Mechanism of ACC. After ACC is subjected to shear force, the shear part of slotted steel tube shrinks continuously and wraps the internal anchor cable (Figure 1(b)). When the free section of anchor cable bears shear force, it is restrained by locks and anchoring section at both ends. At this time, it could be seen as the simply supported beam under concentrated force. Assuming that the concentrated force acts in the middle of the simply supported beam and the length of the free section of anchor cable is $l(\mathrm{~m})$, according to the relevant formulas of material mechanics, the stress situation of anchor cable at the shear plane in elastic stage can be deduced as follows [23]:

$$
\begin{aligned}
M & =\frac{F_{S} l}{4}, \\
\sigma & =\frac{32 M}{\pi D^{2}}+\sigma_{1}=\frac{8 F_{S} l}{\pi D^{2}}+\sigma_{1}, \\
\tau & =\frac{F_{S}\left(\pi R^{2} / 2\right)(4 R / 3 \pi)}{I_{z} 2 R}=\frac{F_{S}\left(\pi R^{2} / 2\right)(4 R / 3 \pi)}{\left(\pi R^{4} / 4\right) 2 R}=\frac{4 F_{S}}{3 A} .
\end{aligned}
$$

It can be seen from formula (2) that when the shear force is fixed, the tensile stress on the anchor cable decreases with the increase of its diameter. After installing the slotted steel tube, when it shrinks and deforms, the shear force acts $0 \mathrm{kN}$ on the anchor cable, due to its certain bearing capacity. It indicates that ACC can absorb a certain shear load to protect the anchor cable, and its limit is $F_{s 1}(\mathrm{kN})$. It can be seen from formula (4) that the contracting stiffness of slotted steel tube $K(\mathrm{kN} / \mathrm{m})$ could be obtained by experiment. When the slotted steel tube and anchor cable form the bearing structure, the diameter of the supporting material is increased, and the additional axial force is reduced [23].

$$
F_{S 1}=K Z=2 K\left(R_{2}-R_{2}^{\prime}\right) \text {. }
$$

It can be seen from formula (3) that the shear stress of anchor cable decreases with the increase of cross-sectional area, which of the whole supporting structure increases due to the installation of slotted steel tube, so ACC bears less shear stress on the shear plane under the same shear force.

$M$ is the bending moment $(\mathrm{N} \cdot \mathrm{m})$ of the anchor cable on the shear plane. $F_{S}$ is the shear load $(\mathrm{N})$ on the anchor cable, $\sigma_{1}$ is the initial axial stress $\left(\mathrm{N} / \mathrm{m}^{2}\right)$ caused by prestress of anchor cable, and $D(\mathrm{~m})$ is the diameter of anchor cable. $\tau$ is the shear stress $\left(\mathrm{N} / \mathrm{m}^{2}\right)$ of the anchor cable on the shear plane. $I_{z}$ is the moment of inertia relative to the neutral axis $\left(\mathrm{m}^{4}\right) . R_{1}(\mathrm{~m})$ is the inner diameter of slotted steel pipe before shrinkage, $R_{2}(\mathrm{~m})$ is the outer diameter, the inner diameter after shrinkage is $R_{1}^{\prime}(\mathrm{m})$, and the outer diameter is $R_{2}^{\prime}(\mathrm{m})$.

\section{Brief Introduction of Double- Shear Instrument}

The schematic diagram and physical drawing of the selfdesigned and developed double-shear test system-tension and shear system of Anchor Cable (bolt) and C-shaped Tube are shown in Figure 2. In this system, the anchor cable is tensioned by locks in the same way as in the work site to provide prestress to the supporting materials. The maximum axial tensile load is 120 tons, and it equips a vertical loading system with a maximum vertical load of 600 tons in the middle. This system can apply shear force to the supporting materials, and the maximum shear displacement is $250 \mathrm{~mm}$.

The test samples are 3 concrete specimens of the same size $300 \mathrm{~mm} \times 300 \mathrm{~mm} \times 300 \mathrm{~mm}$ with $32 \mathrm{~mm}$ prefabricated 


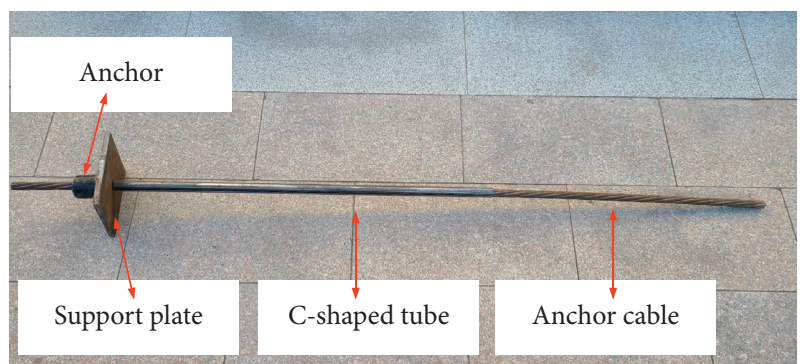

(a)

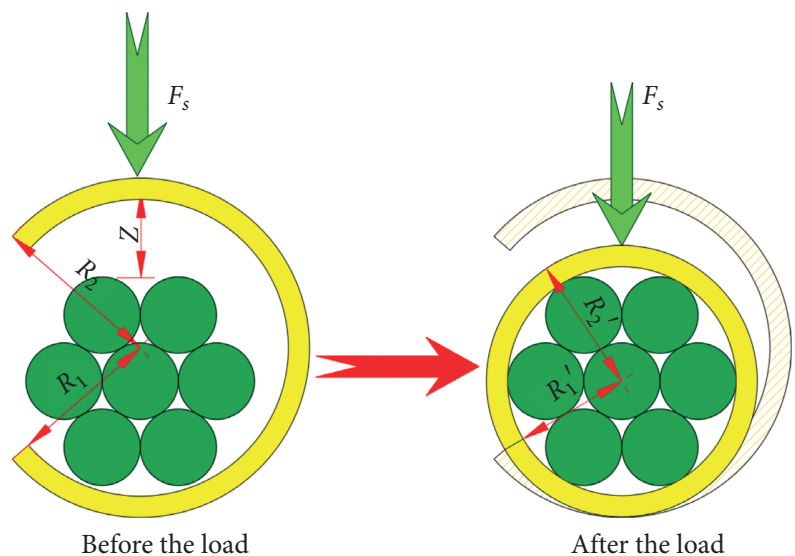

(b)

Figure 1: Physical drawing and schematic of ACC. (a) Physical drawing of the ACC. (b) Schematic diagram of action form of ACC.

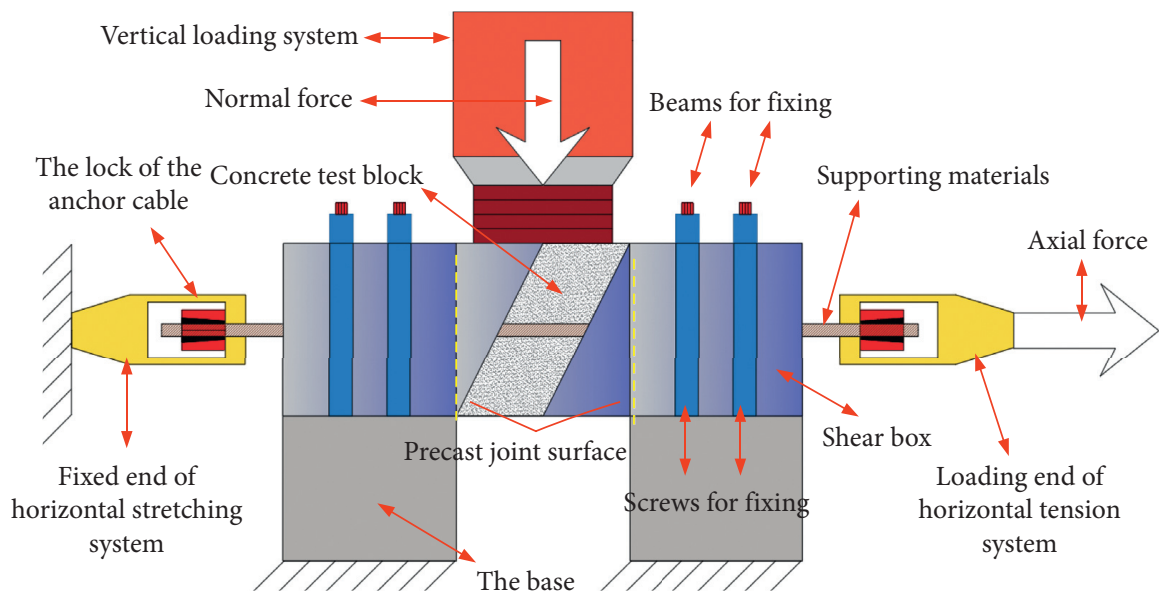

(a)

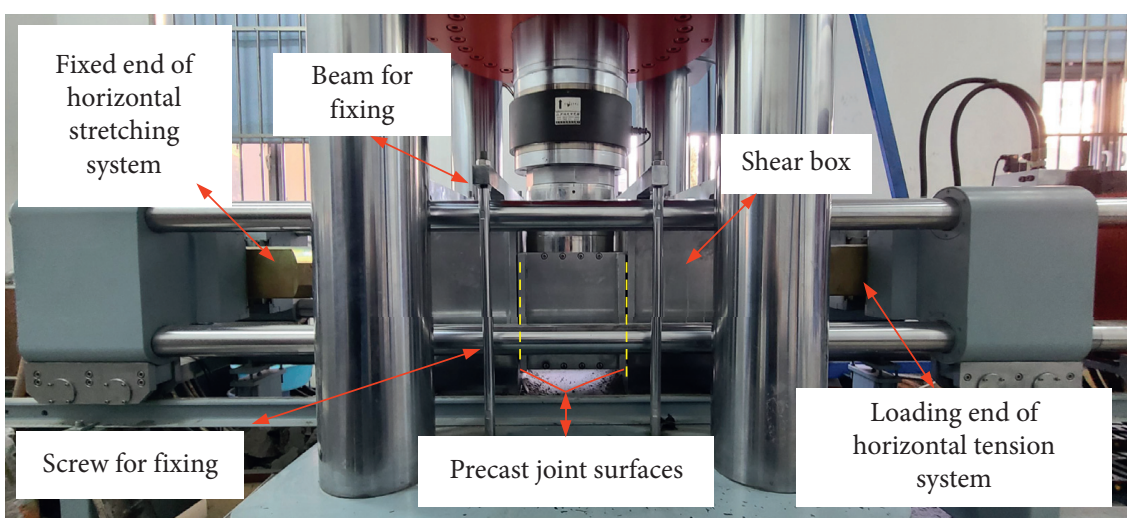

(b)

Figure 2: Sketch map of tension and shear system of Anchor Cable (bolt) and C-shaped Tube. (a) Diagram of instrument. (b) Physical drawing of the instrument.

holes in the middle, in which the supporting materials are installed for further tests. The test samples are restrained by three independent stainless steel shear boxes (Figure 2), and the shear boxes on both sides are restrained, respectively, by four beams and four screws. It can be seen from the schematic diagram in Figure 2(a) that the instrument has no force on the prefabricated joint plane but pure shear force, so the smooth joint plane is what the experiment studies. 


\section{Test Design and Preparation}

In this experiment, double-shear tests were carried out on anchor cables with the diameter of $21.6 \mathrm{~mm}$ and the same type of ACCs, in order to study the influence of different prestress on the shear performance of anchor cable and analyze the effect of ACC supporting structure on the shear mechanical properties of anchor cables after the addition of C-shaped tube into ACC supporting structure. Table 1 is the test design table for this experiment. The specification of concrete specimen used in the test was $300 \mathrm{~mm} \times 300 \mathrm{~mm} \times 300 \mathrm{~mm}$, and the ratio of water: cement: sand: gravel was $1: 2: 4: 4$. After pouring the specimen, a $100 \mathrm{~mm} \times 100 \mathrm{~mm}$ small specimen was left for uniaxial compression test to determine the uniaxial compressive strength of the large specimen, which is shown in Table 1. The uniaxial compressive strength of the test block was determined as $30 \mathrm{MPa}$ according to the results of uniaxial compression test, and some test blocks are shown in Figure 3.

\section{Analysis of Test Results}

The test results are plotted in Figure 4 and summarized in Table 2 after the experiment. Due to a certain gap between the test block and the shear box, there will be a stage where the shear displacement increases, while the shear force remains unchanged during the test; and the effective shear displacement in the table refers to the shear displacement without this initial stage of the test.

5.1. Breaking Law of Supporting Materials. The breaking law of the anchor cables with the diameter of $21.6 \mathrm{~mm}$ in doubleshear test is as follows. It can be seen from Figures 4(a) and 4(b) that it is not the same for the law between the curves of shear force-shear displacement and axial force-shear displacement. The shear force-shear displacement curve is divided into three stages: elastic stage (Figure 4(a), A), short shear yield stage (Figure $4(\mathrm{a}), B$ ), and fracture stage (Figure $4(\mathrm{a}), C)$. The axial force has a relaxation stage (Figure 4(b), A) with the increase of shear displacement. This relaxation phenomenon is more common with the increase of prestress of anchor cable. The reason for the relaxation stage is that a part of the prestress will be transformed into resistance to the deformation of joint surface in the initial stage of shear deformation; and then it will enter the elastic stage (Figure 4(b), B), followed by the long plastic strengthening stage (Figure 4(b), C), and finally break (Figure 4(b), D).

The breaking law of ACC of the anchor cables with the diameter of $21.6 \mathrm{~mm}$ in double-shear test is as follows.

As can be seen from Figures 4(c) and 4(d), the relationship between the shear force-shear displacement curves of ACC has gone through four stages. Stage A is stiffness strengthening stage (Figure $4(\mathrm{c}), A)$. Stage B is elastic stage (Figure 4(c), B). Stage $C$ is shear yield stage (Figure 4(c), C). Stage $\mathrm{D}$ is fracture stage (Figure $4(\mathrm{c}), D$ ); and the four stages are same for the axial force and anchor cable, shown in
Figure 4(d). In the stage a of shear force-shear displacement curve, when ACC is under shear load, the slotted steel pipe can shrink with the increase of shear displacement to wrap the anchor cable, so that the slotted steel pipe and the anchor cable can bear the load together, which improves the initial shear stiffness of the support material.

5.2. Analysis of Material Failure Mode. Breaking the concrete after experiment, it is required to analyze the failure mode of supporting material and concrete blocks. Figure 5 shows some representative blocks and supporting materials after demolition. Figures 5(a) and 5(b) correspond to the test number DS3, and Figures 5(c) and 5(d) to the test number DS8, which are the double-shear test breaking diagrams of anchor cables with the diameter of $21.6 \mathrm{~mm}$ and the same type of ACC under the prestress of $200 \mathrm{kN}$.

The failure mode of concrete block is as follows.

It can be seen from Figures 5(a) and 5(c) that, in the process of double-shear test, severe plastic compression failure occurs at the lower part of the shear plane near the joint surface of the left and right concrete blocks and the upper part of the shear plane on the left and right sides of the intermediate block, which result from directly being affected by supporting material, and it becomes a cone-shaped failure plane.

During the double-shear test, the intermediate block is continuously subjected to the reaction force of supporting material. Plastic deformation occurs continuously on concrete blocks until the whole block splits from parallel drilling direction, because the stiffness of it is lower than that of the supporting material. However, due to the limitation of the shear box, the test block can still apply the load on the supporting material, the test block continues to expand, and the crack continues to expand until the supporting material is broken.

Crack propagation mode of the test block indicates that the cracks of the concrete block are radial after the doubleshear test of the anchor cables with the diameter of $21.6 \mathrm{~mm}$, while those of the concrete block of the ACC of anchor cables with the diameter of $21.6 \mathrm{~mm}$ are split. This is because the anchor cable is structured by many steel strands which makes uneven reaction force on the surrounding rock and increases the possibility of stress concentration. However, the C-shaped tube of ACC is circular, which can reduce the degree of stress concentration and the damage to surrounding rock.

The failure mode of supporting materials is as follows.

It can be seen from Figures 5(b) and 5(d) that the supporting material presents with the shape of spreading wing after being sheared and is broken near the shear plane. Through the analysis of the fracture of two kinds of supporting materials, it is found that there is obvious necking phenomenon in the fracture of two kinds of anchor cables, and the anchor cables are tensile fracture. ACC is protected by slotted steel pipe. When subjected to shear force, the C-shaped tube near the shear plane shrinks to wrap the anchor cable and bear the load together with the anchor cable. When anchor cables break successively inside, there 
TABle 1: Double-shear test schedule.

\begin{tabular}{lccc}
\hline Number & Material type & Prestress $(\mathrm{kN})$ & Average uniaxial compressive strength of specimen $(\mathrm{MPa})$ \\
\hline DS1 & Anchor cables with the diameter of $21.6 \mathrm{~mm}$ & 100 & 31 \\
DS2 & ACC with the diameter of $21.6 \mathrm{~mm}$ & 100 & 28 \\
DS3 & Anchor cables with the diameter of $21.6 \mathrm{~mm}$ & 150 & 32 \\
DS4 & ACC with the diameter of $21.6 \mathrm{~mm}$ & 150 & 30 \\
DS5 & Anchor cables with the diameter of $21.6 \mathrm{~mm}$ & 200 & 33 \\
DS6 & ACC with the diameter of $21.6 \mathrm{~mm}$ & 200 & 33 \\
DS7 & Anchor cables with the diameter of $21.6 \mathrm{~mm}$ & 250 & 32 \\
DS8 & ACC with the diameter of $21.6 \mathrm{~mm}$ & 250 & 31 \\
DS9 & Anchor cables with the diameter of $21.6 \mathrm{~mm}$ & 300 & 31 \\
DS10 & ACC with the diameter of $21.6 \mathrm{~mm}$ & 300 & \\
\hline
\end{tabular}

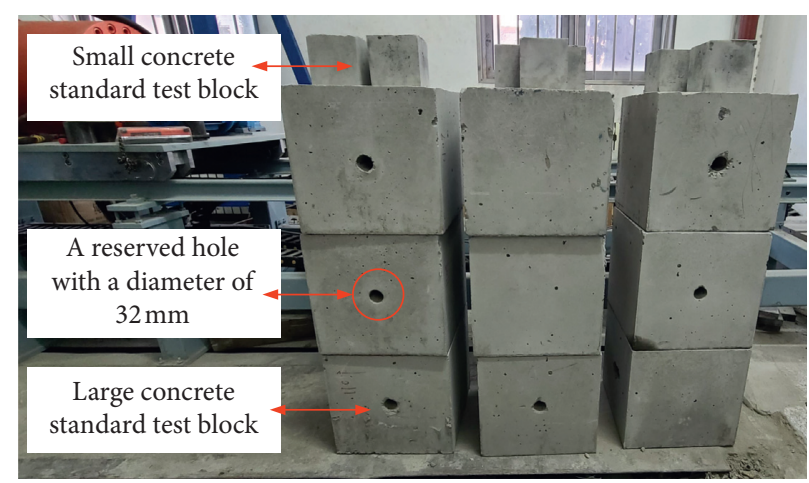

Figure 3: Part of the test blocks.
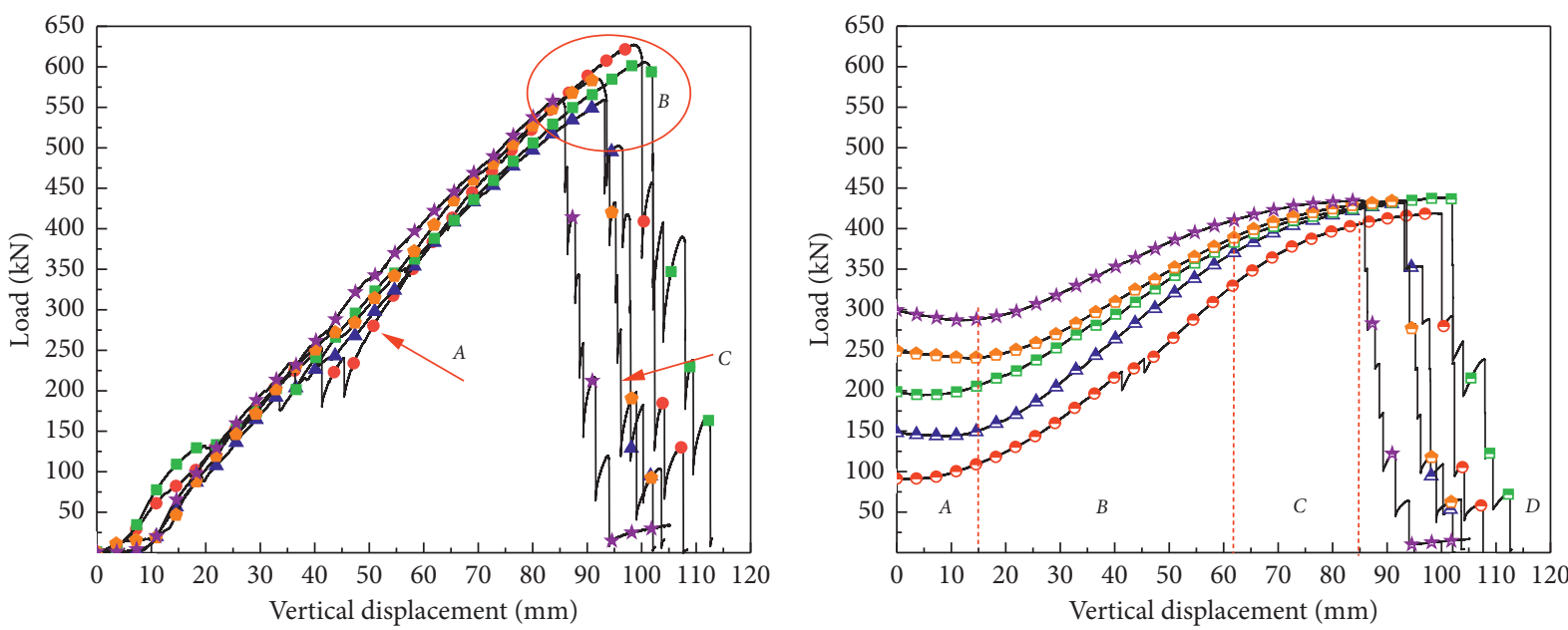

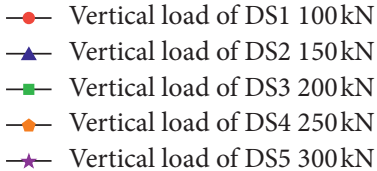

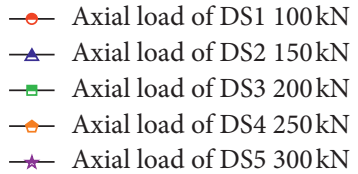

(a)

(b)

Figure 4: Continued. 


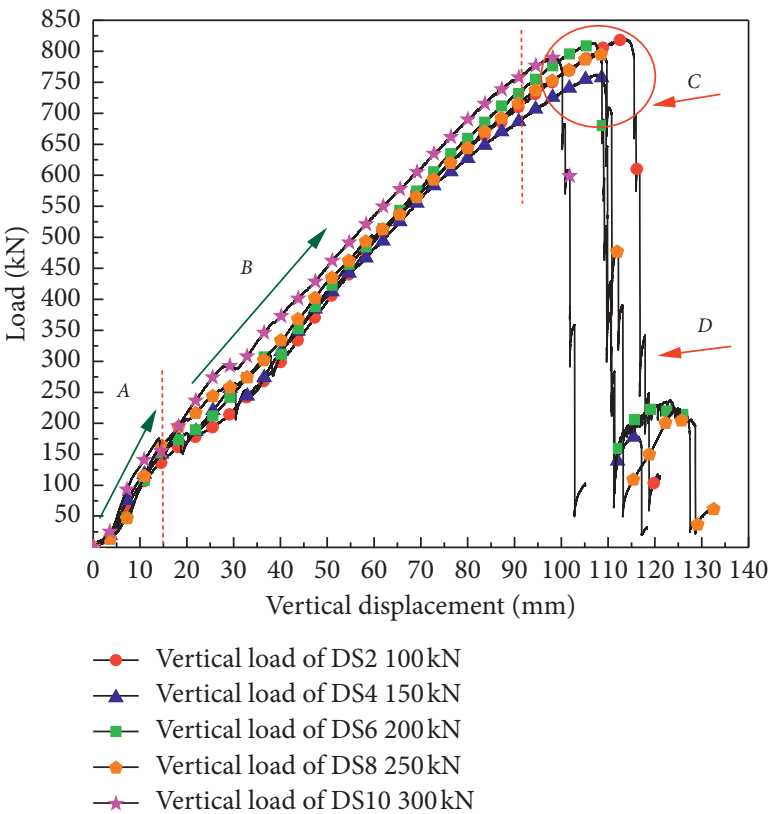

(c)

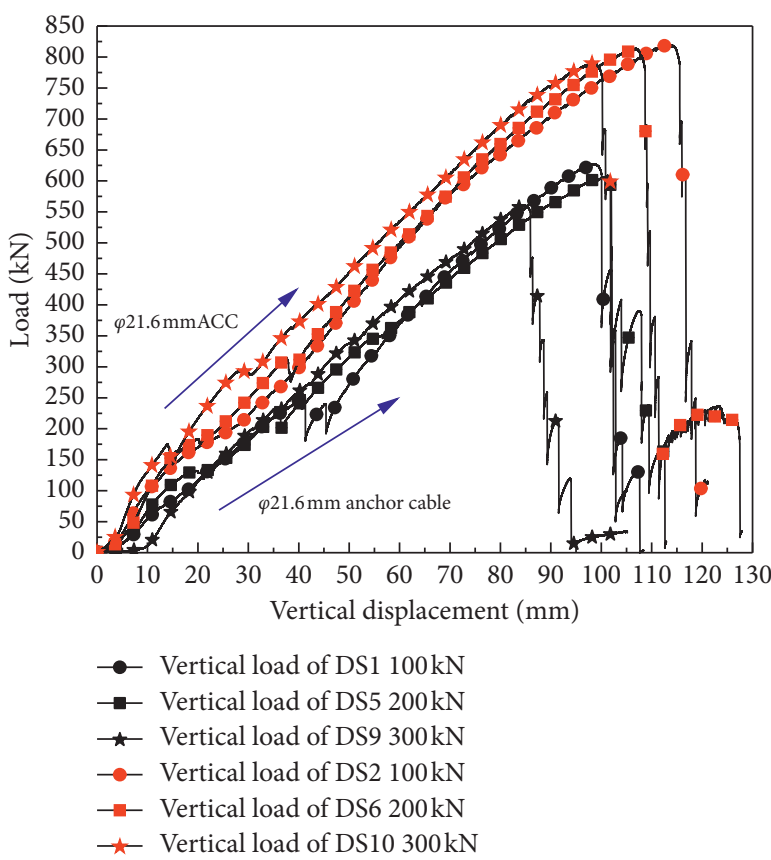

(e)

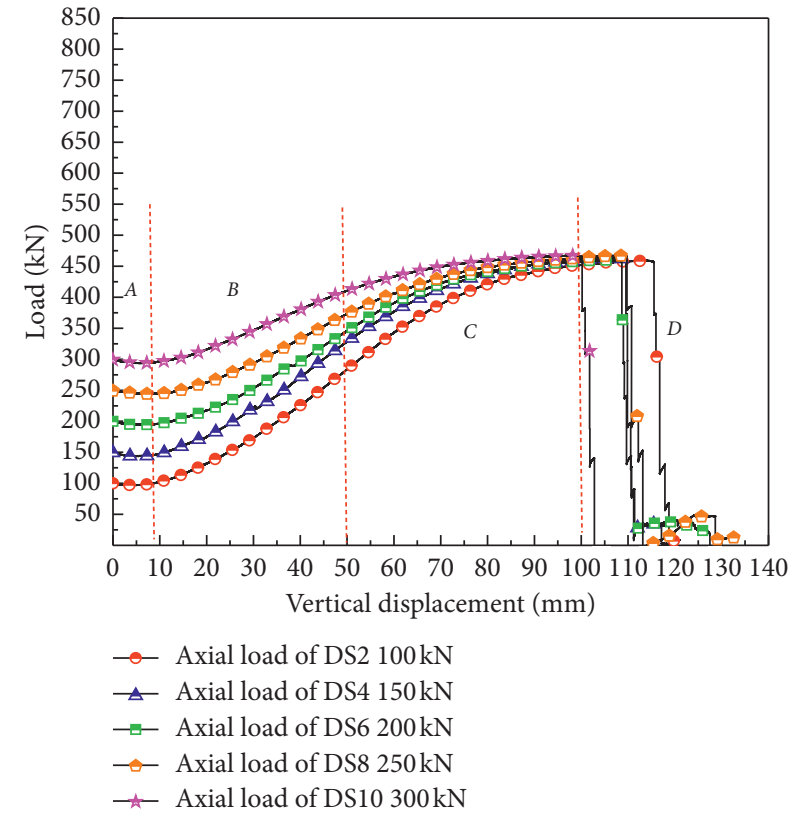

(d)

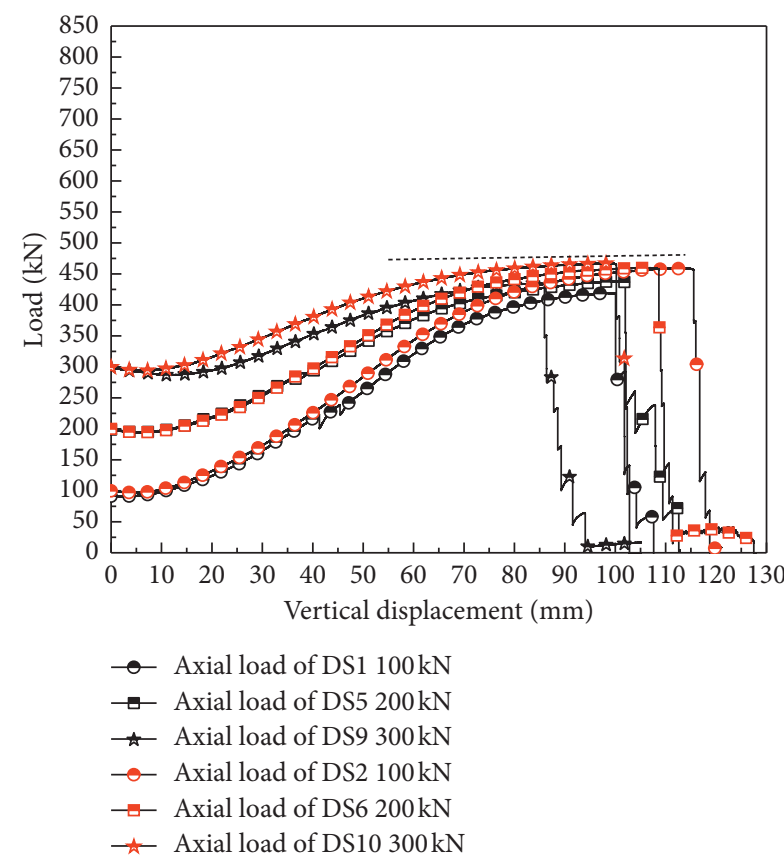

(f)

Figure 4: Data from the double-shear experiment. (a) Normal force displacement relationship of anchor cables with the diameter of $21.6 \mathrm{~mm}$. (b) Axial force displacement relationship of anchor cables with the diameter of $21.6 \mathrm{~mm}$. (c) Normal force displacement relationship of ACC with the diameter of $21.6 \mathrm{~mm}$. (d) Axial force displacement relationship of ACC with the diameter of $21.6 \mathrm{~mm}$. (e) Comparison of normal force displacement relationship between anchor cables with the diameter of $21.6 \mathrm{~mm}$ and the same type of ACC. (f) Comparison of axial force displacement relationship between the anchor cables with the diameter of $21.6 \mathrm{~mm}$ and the same type of ACC.

are no steel strands supporting on one side of the internal C-shaped tube. But, at this time, it has been locked by the expanded rock sample to bear both shear and tension force under shear force; and the tensile-shear failure occurs once the C-shaped tube reaches the limit of bearing capacity.
5.3. Analysis of Bearing Capacity of Supporting Materials. Analysis of shear bearing performance: it can be seen from Figure 4(e) that, with the increase of shear displacement, ACC with C-shaped tube on anchor cable has significantly higher ability to resist shear deformation than that of the 
TABle 2: Statistics of double-shear test data.

\begin{tabular}{|c|c|c|c|c|c|c|c|c|}
\hline Number & $\operatorname{MSBC}(\mathrm{kN})$ & SDMSC $(\mathrm{mm})$ & $\mathrm{ESD}(\mathrm{mm})$ & MABC $(\mathrm{kN})$ & ESDMSC $(\mathrm{mm})$ & ORSBC (\%) & ORSD (\%) & ORABC (\%) \\
\hline DS1 & 627.5 & 108.4 & 106.1 & 419.2 & 106.1 & - & - & \\
\hline DS2 & 818.9 & 126.3 & 120.1 & 459.4 & 120.1 & 30.5 & 13.2 & 9.6 \\
\hline DS3 & 559.4 & 126.5 & 93.5 & 432.3 & 93.5 & - & - & \\
\hline DS4 & 762.3 & 118.3 & 117.2 & 463.0 & 117.2 & 36.3 & 25.3 & 7.1 \\
\hline DS5 & 605.7 & 100.8 & 97.4 & 438.6 & 97.4 & - & - & \\
\hline DS6 & 813.7 & 127.9 & 126.4 & 459.9 & 126.4 & 34.3 & 29.8 & 4.9 \\
\hline DS7 & 585.4 & 104.1 & 102.2 & 435.2 & 102.2 & - & - & \\
\hline DS8 & 795.2 & 133.1 & 132.8 & 467.6 & 132.8 & 35.8 & 29.9 & 7.4 \\
\hline DS9 & 560.2 & 105.1 & 97.3 & 435.2 & 97.3 & - & - & \\
\hline DS10 & 791.3 & 105.1 & 104.2 & 467.3 & 104.2 & 41.3 & 7.1 & 7.4 \\
\hline
\end{tabular}

MSBC: maximum shear bearing capacity, SDMSC: shear displacement at maximum shear capacity, ESD: effective shear displacement, MABC: maximum axial bearing capacity, ESDMSC: effective shear displacement at maximum shear capacity, ORSBC: optimization rate of shear bearing capacity, ORSD: optimization rate of shear displacement, ORABC: optimization rate of axial bearing capacity.
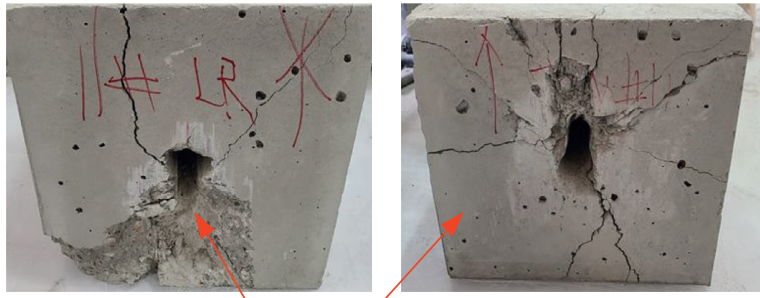

Left precast joint plane

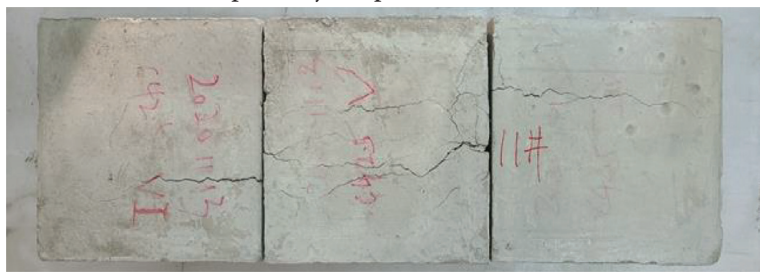

Right precast joint plane
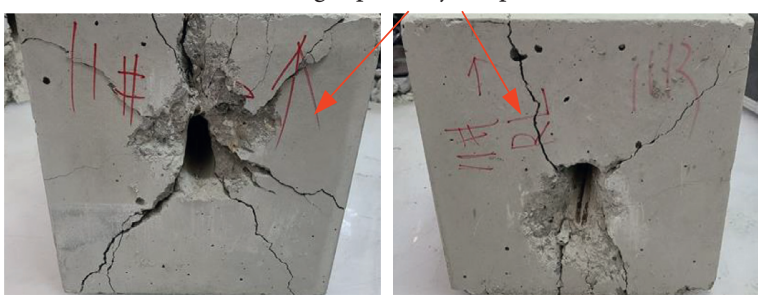

(a)
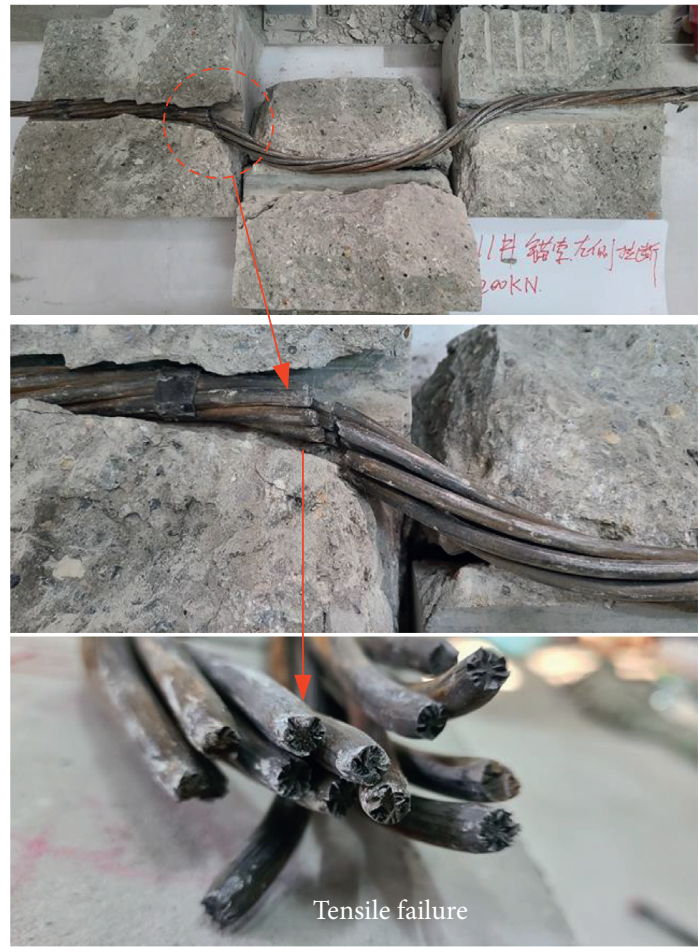

(b)

Figure 5: Continued. 


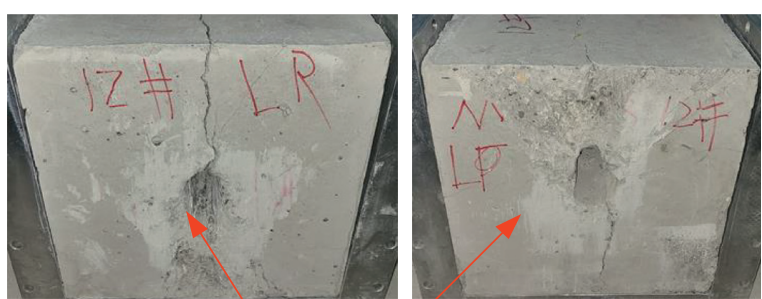

Left precast joint plane

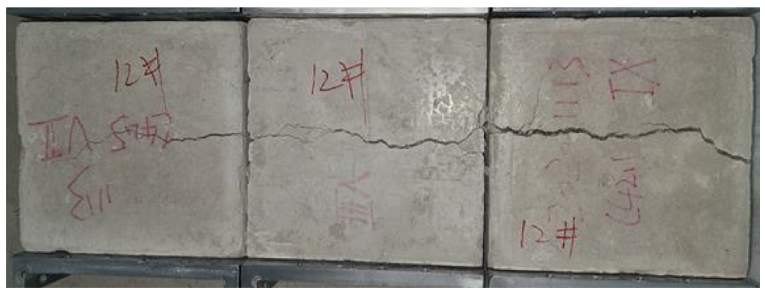

Right precast joint plane

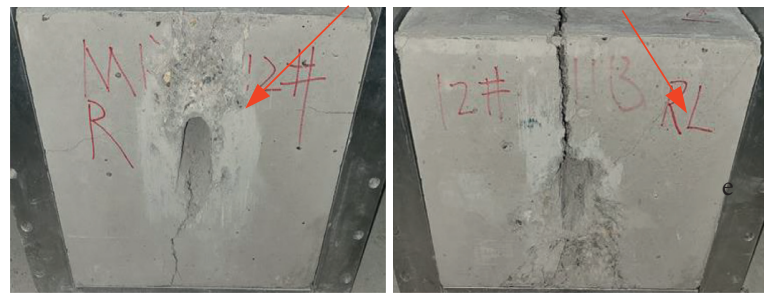

(c)
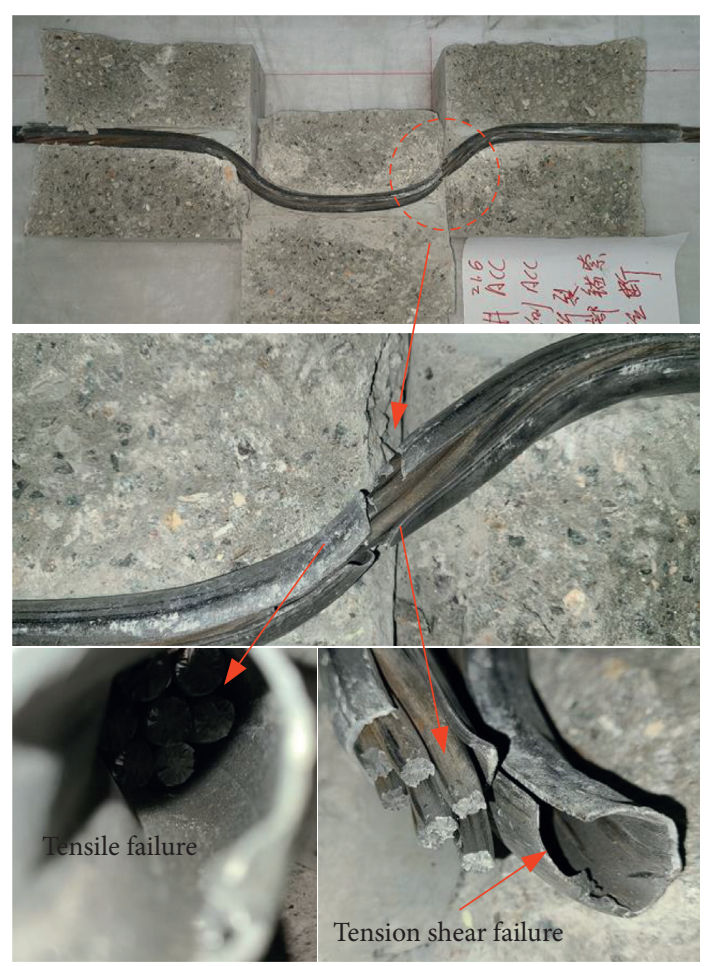

(d)

Figure 5: Display of material failure forms. (a) Failure diagram of anchor cables with the diameter of $21.6 \mathrm{~mm}$ test block. (b) Schematic diagram of breaking of anchor cables with the diameter of $21.6 \mathrm{~mm}$. (c) Failure diagram of ACC with the diameter of $21.6 \mathrm{~mm}$ test block. (d) Fracture diagram of ACC with the diameter of $21.6 \mathrm{~mm}$.

same type of anchor cable. Under the same shear displacement, the shear force of anchor cables with different prestress is generally less than that of ACC, and the shear displacement of ACC is also larger than that of the same type of anchor cable when reaching the limit of shear capacity. It shows that ACC can improve the shear stiffness and ultimate bearing capacity of internal anchor cable.

The key data of double-shear test are listed in Table 2. Figure 6(a) shows the shear capacity and shear displacement at ultimate shear capacity of anchor cables with the diameter of $21.6 \mathrm{~mm}$ with the increase of prestress under the same conditions. It can be seen from Table 2 and Figure 6(a) that, with the increase of preload, the shear bearing capacity of the anchor cable has a downward trend, while the shear displacement is not significantly affected.

Figure 6(b) shows the shear capacity and shear displacement of ACC with the diameter of $21.6 \mathrm{~mm}$ with the increase of prestress under the same conditions. It can be seen from the figure that when the $\mathrm{C}$-shaped tube becomes supporting structure of ACC, the shear bearing capacity is greatly improved, and its shear capacity has been greatly increased by at least $30.5 \%$. Compared with the anchor cables with the diameter of $21.6 \mathrm{~mm}$, the shear displacement also increases to a certain extent, with the minimum increasing by $7.1 \%$ and the maximum by $29.9 \%$.

By comparing the two types of data, it can be seen that the ACC supporting structure improves the shear bearing capacity of the internal anchor cable, and, after using the ACC supporting structure, it can have a stronger ability to resist shear deformation.

In the analysis of axial bearing capacity, it can be seen from Figure 4(f) that when it reaches the ultimate shear capacity, the value of ultimate axial bearing capacity of both the anchor cable and ACC is close; namely, the greater the prestress, the slower the growth rate of axial force with the increase of shear displacement, but ultimately it reaches the tensile yield load with similar numerical value. According to the statistical data in Table 2, compared with the anchor cable, the ultimate tensile load of ACC supporting structure has been slightly optimized, with the maximum optimization rate of $9.6 \%$ and the minimum of $4.9 \%$.

Above all, the ultimate shear capacity of the anchor cable is negatively correlated with the prestress. Under the same prestress, ACC can enhance the shear stiffness of the internal anchor cable and the resistance of shear deformation with a lifting rate of more than $7.1 \%$; it can also increase the 


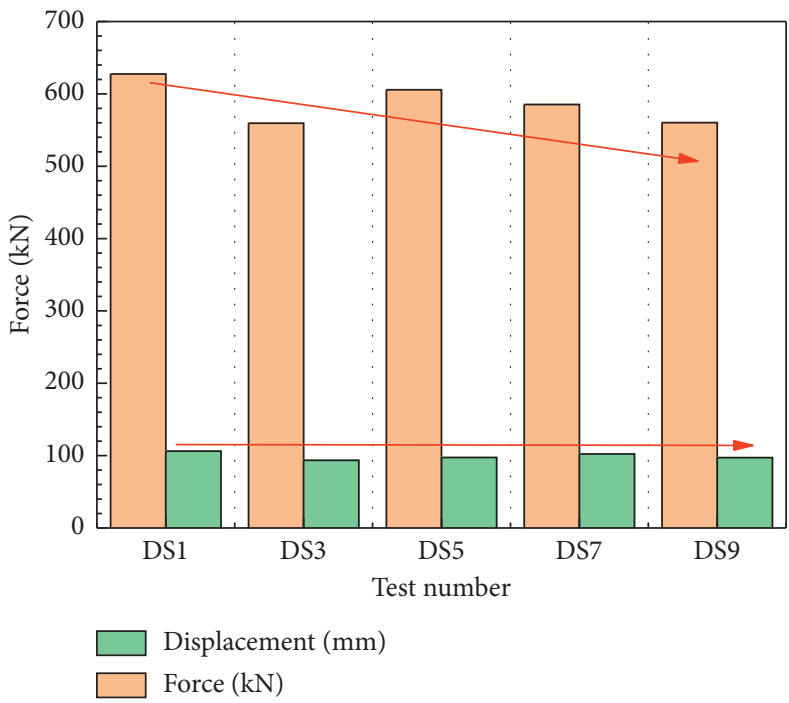

(a)

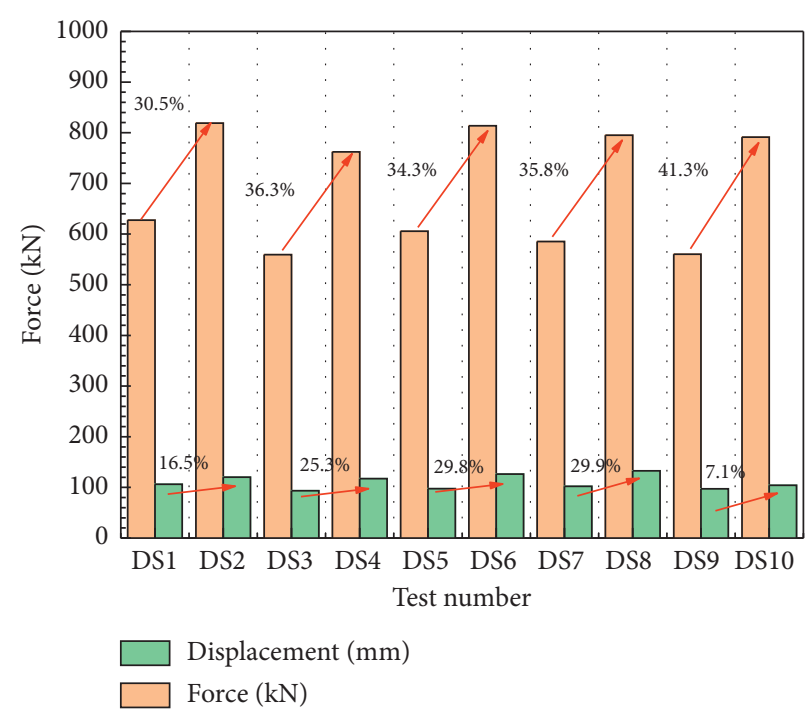

(b)

FIGURE 6: Comparison of shear bearing capacity of supporting materials. (a) Analysis of shear bearing capacity of the anchor cables with the diameter of $21.6 \mathrm{~mm}$. (b) Comparison of bearing capacity between anchor cables with the diameter of $21.6 \mathrm{~mm}$ and the same type of ACC.

ultimate shear capacity of the internal anchor cable with a lifting rate of more than $30.5 \%$. ACC can improve the axial bearing capacity of the inner cable by a small margin, which is more than $4.9 \%$.

\section{Conclusion}

Through the double-shear test of the prestressed anchor cable with diameter of $21.6 \mathrm{~mm}$ and ACC supporting structure of the same type, the following conclusions are obtained:

(1) There is a negative correlation between the ultimate shear capacity of anchor cable and its prestress. The greater the pretension, the weaker the shear capacity. Therefore, the shear bearing capacity of the free section of the prestressed anchor cable will be reduced when the high pretightening force is applied, and there is a risk of shear fracture.

(2) Through the analysis of the failure mode of surrounding rock on both sides of joint surface, it is found that the stress concentration of ordinary anchor cable will occur in the process of shearing due to the structure of steel strand itself, which will deepen the damage to the surrounding rock of structural plane. However, ACC could alleviate the degree of stress concentration of the interaction between supporting structure and surrounding rock and reduce the damage to surrounding rock.

(3) ACC can improve the shear stiffness and the resistance of shear deformation of the internal anchor cable under the same prestress, with the lifting rate of more than 7.1\%; the ultimate shear capacity of the internal anchor cable can be increased by more than $30.5 \%$; and the axial bearing capacity of the internal anchor cable can be slightly improved by more than
$4.9 \%$. ACC supporting structure has the ability to eliminate shear fracture of anchor cable with high prestress in free section.

\section{Data Availability}

The experimental data were obtained from experimental equipment independently designed by China University of Mining and Technology in Beijing.

\section{Conflicts of Interest}

The authors declare that they have no conflicts of interest.

\section{References}

[1] X. Yang, C. Hu, J. Liang et al., "A case study on the control of large deformations in a roadway located in the du'erping coal mine in China," Advances in Materials Science and Engineering, vol. 2019, Article ID 9628142, 13 pages, 2019.

[2] C. Zang, M. Chen, G. Zhang, K. Wang, and D. Gu, "Research on the failure process and stability control technology in a deep roadway: numerical simulation and field test," Energy Science \& Engineering, vol. 8, no. 7, pp. 2297-2310, 2020.

[3] Q. Wang, B. Jiang, R. Pan et al., "Failure mechanism of surrounding rock with high stress and confined concrete support system," International Journal of Rock Mechanics and Mining Sciences, vol. 102, pp. 89-100, 2018.

[4] G. U. O. Zhibiao, L. Zhang, H. Wang et al., "Failure mechanism of bolts and countermeasures in swelling soft rock support," Tehnicki Vjesnik-Technical Gazette, vol. 25, no. 5, pp. 1447-1456, 2018.

[5] Y. Yu, X. Wang, J. Bai, L. Zhang, and H. Xia, "Deformation mechanism and stability control of roadway surrounding rock with compound roof: research and applications," Energies, vol. 13, no. 6, Article ID 1350, 2020.

[6] S. R. Wang, Y. H. Wang, J. Gong, Z. L. Wang, Q. X. Huang, and F. L. Kong, "Failure mechanism and constitutive relation 
for an anchorage segment of an anchor cable under pull-out loading," Acta Mechanica, vol. 231, no. 8, pp. 3305-3317, 2020.

[7] A. M. Ferrero, "The shear strength of reinforced rock joints," International Journal of Rock Mechanics and Mining Sciences \& Geomechanics Abstracts, vol. 32, no. 6, pp. 595-605, 1995.

[8] T. Xiao, H. Li, Y. Xu et al., "Fracture mechanism and control of coal roadway shoulder anchor in deep tectonic stress area," Geotechnical Mechanics, vol. 8, pp. 2303-2308, 2013.

[9] X. Li, N. Aziz, A. Mirzaghorbanali, and J. Nemcik, "Behavior of fiber glass bolts, rock bolts and cable bolts in shear," Rock Mechanics and Rock Engineering, vol. 49, no. 7, pp. 27232735, 2016.

[10] Q. Liu, G. Lei, and X. Peng, "Research progress and thinking on anchorage mechanism of deep fractured rock mass," Journal of Rock Mechanics and Engineering, vol. 35, no. 2, pp. 312-332, 2016.

[11] R. Yang, "Experimental study on shear mechanical properties of prestressed anchor cables," Journal of China University of Mining and Technology, vol. 47, no. 6, pp. 1166-1174, 2018.

[12] N. Aziz, H. Rasekh, A. Mirzaghorbanali, G. Yang, S. Khaleghparast, and J. Nemcik, "An experimental study on the shear performance of fully encapsulated cable bolts in single shear test," Rock Mechanics and Rock Engineering, vol. 51, no. 7, pp. 2207-2221, 2018.

[13] A. Mirzaghorbanali, H. Rasekh, N. Aziz, G. Yang, S. Khaleghparast, and J. Nemcik, "Shear strength properties of cable bolts using a new double shear instrument, experimental study, and numerical simulation," Tunnelling and Underground Space Technology, vol. 70, pp. 240-253, 2017.

[14] H. Lin, Y. Zhu, J. Yang, and Z. J. Wen, "Anchor stress and deformation of the bolted joint under shearing," Advances in Civil Engineering, vol. 2020, Article ID 3696489, 10 pages, 2020.

[15] H. Lin, X. Zhang, Y. X. Wang et al., "Improved nonlinear Nishihara shear creep model with variable parameters for rock-like materials," Advances in Civil Engineering, vol. 2020, Article ID 7302141, 15 pages, 2020.

[16] M. He, W. Gong, J. Wang et al., "Development of a novel energy-absorbing bolt with extraordinarily large elongation and constant resistance," International Journal of Rock Mechanics and Mining Sciences, vol. 67, pp. 29-42, 2014.

[17] M. C. He and Z. Guo, "Mechanical property and engineering application of anchor bolt with constant resistance and large deformation," Chinese Journal of Rock Mechanics and Engineering, vol. 33, pp. 1297-1308, 2014, in Chinese.

[18] M. C. He, C. Li, W. Gong et al., "Support principles of NPR bolts/cables and control techniques of large deformation," Chinese Journal of Rock Mechanics and Engineering, vol. 35, pp. 1513-1529, 2016, in Chinese.

[19] H Kang, J. Wang, and J. Lin, "High prestressed strong support system and its application in deep roadway," Acta Coal Sinica, vol. 12, pp. 1233-1238, 2007.

[20] B. Hu, H. P. Kang, and J. Lin, "Comparison and application of high prestress and intensive support system in close, soft and cracked roadway support," Advanced Materials Research, vol. 29, pp. 524-527, 2012.

[21] H. Kang, Y. Wu, and F. Gao, "Deformation characteristics and reinforcement technology for entry subjected to mining-induced stresses," Journal of Rock Mechanics and Geotechnical Engineering, vol. 3, no. 3, pp. 207-219, 2011.

[22] R. Shan, P. Huang, H. Yuan et al., "Research on the fullsection anchor cable and C-shaped tube support system of mining roadway in island coal faces," Journal of Asian Architecture and Building Engineering, p. 12, 2021.

[23] S. Yan, Mechanics of Materials, The Science Publishing Company, New York, NY, USA, 2012. 